\title{
Os gêneros e formatos da ficção televisiva reinventados na Ibero-América
}

Tissiana Nogueira Pereira

Doutoranda em Ciências da Comunicação pela Escola de Comunicação e Artes da Universidade de São Paulo. Mestre em Comunicação Midiática pela Universidade Federal de Santa Maria. Jornalista.

E-mail: tissianapereira@yahoo.com.br

Resumo: A resenha apresenta um apanhado dos principais dados abordados no Anuário Obitel 2016 - (Re)lnvenção de Gêneros e Formatos da Ficção Televisiva, coordenado por Maria Immacolata Vassallo de Lopes e Guillermo Orozco Gómez. O livro é fruto de pesquisas colaborativas em 12 países ibero-americanos que realizam um mapeamento da ficção televisiva local, investigando os processos de produção, consumo, comercialização e recepção de ficção televisiva com base em um protocolo metodológico unificado, combinando abordagens quantitativas e qualitativas. $\mathrm{Na}$ sua décima edição, o anuário expõe ainda discussões sobre a (re)invenção de gêneros e formatos da ficção televisiva, atentando para as transformações percebidas nas narrativas ficcionais tanto em conteúdo quanto na combinação de diversos gêneros, serialidades e formatos.

Palavras-chave: ficção televisiva; Obitel; gêneros; formatos; reinvenção.
Abstract: This review presents a selection of the main data presented on the Obitel 2016 Annuary - (Re)Invention of Genres and Formats in Fiction Television, coordinated by Maria Immacolata Vassallo de Lopes and Guillermo Orozco Gómez. The book is the result of collaborative researches in 12 ibero-american countries that have mapped their local fiction televison, investigating production processes, consumption, comercialization and reception of fiction television, based upon na unified methodological protocol that combines both quantitative and qualitative approaches. In its tenth edition, the annuary also presents discussion about the (re)invention of genre and formats in fiction television, focusing on transformation of fictional narratives, both in content as well as in a combination of genre, serialities and formats..

Keywords: television fiction; Obitel; genres; formats; reinvention.

O Obitel se consolida cada vez mais no campo ibero-americano da Comunicação como uma rede internacional de pesquisa que investiga os processos de produção, consumo, comercialização e recepção de ficção televisiva com base 
1. LOPES, Maria Immacolata Vassallo de; OROZCO GÓMEZ, Guillermo (orgs.). Anuário Obitel 2016 - (Re) Invenção de Gêneros e Formatos da Ficção Televisiva. Porto Alegre: Sulina, 2016.

2. Disponíveis em: $<w w w$. obitel.net/?page_id $=8 \&$ lang=pt $>$. Acesso em: 21 nov. 2016.

3. Os países que compõem a rede Obitel atualmente são: Argentina, Brasil, Chile, Colômbia, Equador, Espanha, Estados Unidos, México, Peru, Portugal, Uruguai e Venezuela.

4. LOPES, Maria Immacolata Vassallo de; OROZCO GÓMEZ, Guillermo (orgs.), op. cit. Porto Alegre: Sulina, 2016. num protocolo metodológico unificado, combinando abordagens quantitativas e qualitativas. Ele tem possibilitado estudos comparativos inéditos sobre a produção ficcional a partir de evidências empíricas sobre a produção de conteúdos em diferentes plataformas, gêneros, formatos, programações que, ao circularem, delineam processos de interculturalidade dos países participantes. O Anuário Obitel 2016 - (Re)Invenção de Gêneros e Formatos da Ficção Televisiva1 é comemorativo pois é a sua décima edição. O livro coordenado por Maria Immacolata Vassalo de Lopes e Guillermo Orozco Gómez, assim como os outros anuários, foi editado em formato digital em português, espanhol e inglês com acesso livre para download ${ }^{2}$. A edição em português foi feita também na versão impressa e distribuída gratuitamente. Quanto à estrutura, o anuário está dividido em três partes. A primeira é formada por uma síntese comparativa da ficção dos 12 países que fazem parte do Obitel $^{3}$, destacando o desenvolvimento da ficção em cada país, as principais produções e o tema do ano, a segunda parte está subdividida em 12 capítulos (um para cada país) e tem uma estrutura de tópicos fixos que são os seguintes: o contexto audiovisual do país; análise da ficção de estreia, recepção transmídia, produções mais destacadas do ano, tema do ano. A terceira parte do anuário é um apêndice que reúne as fichas técnicas dos dez títulos de ficção mais vistos em cada país com as informações básicas sobre tais produções.

Acerca dos aspectos gerais de produção abordados no Anuário 2016, destaca-se um predomínio de canais privados (70\%) nos países Obitel sobre os públicos (30\%), o que vem se mantendo ao longo dos 11 anos de monitoramento. Com exceção de Portugal, que tem o mesmo número de canais públicos e privados, e Estados Unidos, que não possuem nenhum canal público em língua espanhola. O livro ainda aponta que o número de canais de televisão em 2015 foi o mesmo de 2014, ressaltando que no México um canal (Cadena Tres) deixou de transmitir para dar lugar a uma nova rede de televisão que entrará ao ar no final de 2016 e que no Uruguai começou a funcionar um novo canal público digital (Tevé Ciudad).

As mudanças tecnológicas, programáticas e narrativas na indústria da ficção em 2015 também são apresentadas no livro. Elas aconteceram porque as corporações midiáticas sofreram mudanças estruturais ao expandirem a novos mercados, levando a um ajuste das estratégias na área digital, mesmo que isso tenha acontecido em meio à crise da queda do rating na televisão na maioria dos países que fazem parte do Obitel. A exemplo de como essas mudanças alteram também os hábitos de consumo das audiências o anuário mostra o Brasil, onde o panorama audiovisual foi marcado pela "reorganização dos hábitos da audiência e pela adesão permanente dos produtores às possibilidades de expansão de conteúdos digitais, especialmente aqueles vinculados à television on demand"4. Assim, são destacados o crescimento do consumo do Netflix, o surgimento do Globo Play em 2015, o TV SBT, Now, Vivo Play para exemplificar a recepção multitela, cada vez mais consolidada no país. Mesmo com essas 
mudanças tecnológicas as audiências continuam fiéis à ficção televisiva em todos os países Obitel.

Tal reestruturação das empresas televisivas, os planos de expansão de mercado e a migração tecnológica das audiências fizeram com que houvesse uma queda nos investimentos publicitários na televisão aberta, o que não indica uma crise e, sim, uma reconfiguração da publicidade que também teve que adequar-se às estratégias multitela. Assim, há a introdução de produtos dentro das tramas, demonstrando que as estratégias de merchandising e as ações socioeducativas (também conhecidas como merchandising social) continuam inseridas nas ficções televisas ibero-americanas, como já apontado em outros anos.

No anuário, foram destacadas as políticas de comunicação e telecomunicações que estão sendo implementadas nos países Obitel desde 2013 e que tiveram desenvolvimento e aplicação importantes no ano de 2015. Como, por exemplo, a Lei do Marco Civil da Internet no Brasil, que incluiu consulta pública para sua regulamentação, e o "apagão tecnológico", que iniciou em fevereiro de 2016 e tem previsão de fim em 2023, além do privilégio da banda larga em detrimento da telefonia fixa no país. Outras leis importantes foram implementadas em outros países ibero-americanos em 2015, como a "neutralidade da rede" nos Estados Unidos, o mercado das telecomunicações como chave para o investimento e o desenvolvimento do México, a Lei Orgânica de Comunicação no Equador, e a expansão definitiva da telefonia móvel $4 \mathrm{G}$ na Colômbia.

Em 2015, foram percebidas algumas tendências no mercado televisivo internacional, como a ocupação das superséries no horário das 23h na Globo no Brasil, o alto consumo das coproduções internacionais em plataformas outras que a TV aberta, como Narcos na Netflix, e o fenômeno das novelas turcas, que foram veiculadas no Brasil, México, Equador, Estados Unidos, Peru, Uruguai, Argentina e Chile.

Os países que produziram mais horas de ficção nacional foram Brasil e México, apesar de este último apresentar queda contínua na produção, pois liderava esse ranking desde 2011. As ficções brasileiras continuam merecendo destaque, como nos anos anteriores, por ocupar os sete primeiros lugares na tabela dos 120 títulos mais vistos em 2015, nos países que fazem parte da rede Obitel. As telenovelas continuam sendo o formato mais produzido, porém, diferente dos anos anteriores, houve uma forte diminuição na produção de séries, que perderam força para formatos de narrativa curta, como minisséries e telefilme, especialmente na Argentina e no Brasil. Os telefilmes tiveram seu crescimento graças à elevada produção do Brasil devido à comemoração dos 50 anos da Globo, em que a emissora exibiu inúmeras ficções de sucesso reeditadas nesse formato.

O tema do ano do Anuário Obitel 2016 foi a "(Re)Invenção de Gêneros e Formatos da Ficção Televisiva". Apesar de o gênero ser uma classificação que pretende organizar o conteúdo em categorias, nem sempre são facilmente identificáveis e estáticos, e, por isso, merecem atenção dos pesquisadores do campo. Assim, 
5. COHEN, 1986 apud CREEBER, Gleen. Introduction of Genre Theory. In: CREEBER, G.; MILLER, T.; TULLOCH, J. (eds.). The Television Genre Book. Londres: $\mathrm{BFI}$ and Palgrave Mac Millan, 2008.

6. MARTÍN-BARBERO, Jesús. Latin America: Cultures in the Communication Media. Journal of Communication, 43(2), 1993.

7. MITTELL, Jason. A Cultural Approach to Television Genre Theory. In: ALLEN, R.; HILL, A. (eds.), The Television Studies Reader. Nova York: Routledge Taylor \& Francis Group, 2004.

8. BOURDIEU, Pierre. Distinction: A Social Critique of the Judgement of Taste. Nova York: Routledge, 2010.

9. LOPES, Maria Immacolata Vassallo de; OROZCO GÓMEZ, Guillermo, op. cit., p. 89.
O conceito de gênero na teoria e na prática surge, muda e declina por razões históricas. Cada gênero é composto de textos que se acumulam, que se agrupam como processo, e não como uma determinada categoria. Os gêneros são categorias abertas. Cada elemento altera o gênero para adicionar, contradizer, ou promover a mudança de seus constituintes, especialmente para os membros que fecham com ele $[\ldots]^{5}$.

Martín-Barbero (1993) ${ }^{6}$ afirma que gênero é o lugar onde acontece a osmose entre os formatos comerciais e as matrizes culturais. Sendo assim, o gênero seria uma estratégia de comunicação, uma forma de organizar e compreender as competências dos emissores e dos receptores. Para Mittell (2004) ${ }^{7}$, a discussão de gênero televisivo diz respeito a processos culturais, assim, tanto o gênero quanto o formato são construções sociais, e muitas vezes, hierarquias de gosto ${ }^{8}$. Dessa forma, em tempos de mudança é imprescindível que se atente para as novas práticas de audiência e como estas afetam as dinâmicas da narrativa e as regras de gênero.

Portanto, em 2015 o Obitel observou que as narrativas de longa serialidade como as telenovelas, que possuem reconhecida estrutura melodramática, ainda são as principais representantes no espaço ibero-americano. Na Argentina, o formato telenovela ainda se impõe, mas a televisão no país começou a experimentar outras estratégias para suprir a demanda das múltiplas telas, como programas em redes sociais e sites. No Brasil, o destaque foi para os exemplos importantes que equilibram as formas serial e série nas telenovelas A Regra do Jogo (Globo, de João Emanuel Carneiro) e Verdades Secretas (Globo, Walcyr Carrasco). A primeira trouxe uma explícita tensão entre capítulo e episódio, visto que "cada capítulo foi numerado e recebeu título que aludia aos acontecimentos do dia", e a segunda, utilizou o formato telenovela na elaboração de ganchos contundentes no final de cada capítulo, associados ao formato série para encadear as ações dramáticas de cada núcleo da trama.

A telenovela ainda é a principal narrativa televisiva no espaço ibero-americano, no que diz respeito ao formato de longa serialidade. Mas está acompanhada pelo aumento das multitelas, bem como o crescimento do VoD. Houve o crescimento também de serviços streaming em todos os países integrantes da rede, tendo inclusive, algumas produções elaboradas especialmente para essas novas plataformas. As coproduções demonstram uma hibridização de televisão e cinema tanto em seus aspectos técnicos como narrativos, sendo os Estados Unidos o país que mais realizou esse tipo de produção.

Desde o anuário de 2010, os pesquisadores focam de forma sistemática no fenômeno da ficção expandida nas múltiplas telas e, no anuário de 2016, houve uma validação de tendências como a diversificação e a hibridização de gêneros e formatos na ficção televisiva ibero-americana. Tais transformações devem crescer ainda mais, seja devido a estratégias mercadológicas ou pelas mudanças na forma de contar as histórias. Isso porque a reinvenção de gêneros e formatos em todos os países acaba por responder às novas demandas postas pelas, também novas, modalidades de consumo. Dessa maneira, cada vez mais 
é preciso atentar para tais transformações e reinvenções para que seja possível apreendê-las, compreendê-las, principalmente porque estas podem cada vez mais influenciar as futuras produções ficcionais.

\section{REFERÊNCIAS BIBLIOGRÁFICAS}

BOURDIEU, Pierre. Distinction: A Social Critique of the Judgement of Taste. Nova York: Routledge, 2010.

CREEBER, Gleen. Introduction of genre theory. In: CREEBER, G.; MILLER, T., TUlloch, J. (eds.). The Television Genre Book. Londres: BFI and Palgrave Mac Millan, 2008.

LOPES, Maria Immacolata Vassallo de; OROZCO GÓMEZ, Guillermo (orgs.). Anuário Obitel 2016 - (Re) Invenção de Gêneros e Formatos da Ficção Televisiva. Porto Alegre: Sulina, 2016.

MARTÍN-BARBERO, Jesús. Latin America: Cultures in the Communication Media. Journal of Communication, 43(2), 1993.

MITTELL, Jason. A Cultural Approach to Television Genre Theory. In: ALLEN, R. e HILL, A. (eds.), The Television Studies Reader. Nova York: Routledge Taylor \& Francis Group, 2004. 